\title{
Sustainable bio-nano composite coatings for the protection of marble surfaces
}

\author{
Yılmaz Ocak ${ }^{a}$, Aysun Sofuoglu ${ }^{a, b, *}$, Funda Tihminlioglu ${ }^{a}$, Hasan Böke ${ }^{c}$ \\ a Department of Chemical Engineering, İzmir Institute of Technology, Urla 35430, Izmir, Turkey \\ ${ }^{\mathrm{b}}$ Environmental Research Center, Izmir Institute of Technology, Urla 35430, Izmir, Turkey \\ c Department of Architectural Restoration, Izmir Institute of Technology, Urla 35430, Izmir, Turkey
}

\section{A R T I C L E I N F O}

\section{Article history:}

Received 26 February 2014

Received in revised form 9 June 2014

Accepted 30 July 2014

Available online 28 August 2014

\section{Keywords:}

PLA/MMT

Nanocomposite

Marble

Protection

$\mathrm{SO}_{2}$

Sulfation reaction

\begin{abstract}
A B S T R A C T
Water repellency on natural stone surfaces is the most important issue in the protection of stone monuments from effects of atmospheric pollutants. In this study, effectiveness of a bio-nano composite coating, composed of a biodegradable polymer (poly-L-lactide [PLA]) and montmorillonite clay (MMT) was investigated for the protection of marble surfaces from pollution. The clay dispersion in polymer matrices was analyzed by using Scanning Tunnel Electron Microscopy (STEM) and X-Ray Diffraction (XRD), while protection performance was investigated by the measurement of surface roughness, wettability, water vapor permeability, capillary water absorption, and color changes on the marble surfaces. As a result, no alteration on the color of coated marbles was observed, significant improvement was obtained for hydrophobicity of the surface and inhibition of sulfation reaction on the exposed marble surfaces under acidic atmosphere. It could be said that PLA based nanocomposites seem to be promising materials as protective coating agents in reducing the effects of water and atmospheric pollutants on marble surfaces. (c) 2014 Elsevier Masson SAS. All rights reserved.
\end{abstract}

\section{Introduction}

Since the early ages, natural stones have been the most commonly used material in construction of buildings, sculptures, temples, etc. in every culture, due to their durability, strength and low maintenance cost. Durability and strength of the stone depend on its mineral composition, pore structure, and pore size distribution which have significant effects on the transport of gas and water vapor from the surface to inside of the stone.

Atmosphere is the main pathway for the transport of gas and particulates to the Earth's surface. Atmospheric pollutants not only cause the detrimental effects on human, animals and vegetation, but also accelerate deterioration of the earth materials. Transport of gases and water vapor initiates the deterioration on the surface of stones due to dissolved pollutant gases emitted from stationary and mobile sources.

\footnotetext{
* Corresponding author. Department of Chemical Engineering, İzmir Institute of Technology, Urla 35430, İzmir, Turkey. Tel.: +90 232750 6650; fax: +902327506645.

E-mail addresses: yilmazocak@iyte.edu.tr (Y. Ocak), aysunsofuoglu@iyte.edu.tr (A. Sofuoglu), fundatihminlioglu@iyte.edu.tr (F. Tihminlioglu), hasanboke@iyte.edu.tr (H. Böke).
}

Deterioration mechanism on the stone starts with the deposition of pollutants on the surface of the material either by dry deposition that is the transfer of gas, particulates and aerosols by wind or gravity, or wet deposition [1]. The most important pollutant responsible for deterioration of stone is sulfur dioxide $\left(\mathrm{SO}_{2}\right)$ gas. $\mathrm{SO}_{2}$ undergoes reaction with marble, composed of mainly calcite $\left(\mathrm{CaCO}_{3}\right)$ crystals, converts $\mathrm{CaCO}_{3}$ into calcium sulphite hemi-hydrate $\left(\mathrm{CaSO}_{3} .1 / 2 \mathrm{H}_{2} \mathrm{O}\right)$ in the presence of the water [2-5]. Then, calcium sulphite hemi-hydrate is rapidly oxidized to gypsum $\left(\mathrm{CaSO}_{4} \cdot 2 \mathrm{H}_{2} \mathrm{O}\right)$ by the oxygen in the presence of water.

Gypsum is a semi-soluble mineral and occupies more volume than calcite crystals. Consequently, the marble surface starts to erode [2-4]. Therefore, many studies have been conducted to protect the stone surfaces from the attack of pollutants and penetration of water and water vapor by using coating agents like acrylic polymers, waxes, fluorinated or partly fluorinated compounds, etc. [6-8].

International Conservation Community of Historic Monuments and Building suggests that the coating agents applied on the stone surfaces should not change their transparency, and should be reversible to allow renewability of the coating without needing extra removal technique of the old coating. Reversibility is defined as a vital condition for conservation products since the treatment applied to an object intended to last for a while should allow renovation without leaving any damage on the original surface. 
However, most of the applied products were neither reversible nor showed enough protection on the surface against the acid attack $[4,9]$. As a result, renewal of irreversible coating agents created more damages compared to uncoated ones due to mechanical removal requirement from the surfaces $[4,10]$.

The use of biodegradable polymer (Poly-L-lactide [PLA]) as a coating agent on the marble surface showed a great potential to fulfill the principles of the International Conservation Community of Historic Monuments and Building. Its protection performance against the acidic atmosphere signified PLA as a new generation coating material for the stone protection [5].

It is reported that even though biodegradable polymers have great commercial potential for many applications, the properties such as brittleness, low-heat distortion temperature, high-gas permeability, low-melt viscosity, etc. limit their use for further processing. Therefore, nano reinforcement in polymers provided an effective way to improve the properties concurrently [11].

Nanoparticle addition into synthetic polymer coatings was used to increase protection efficiency of stone surfaces in a few investigations. Use of silicone containing polymer matrices formed by siloxane cage penetrated by fluoropolymer, polyolefin and acrylic resins [12]; nanosilica added flouro alkylsilane [13]; silica added polymethyl methacrylate (PMMA) and functionalized perfluorinated polyether (PFPE) [14]; organoclay addition into epoxy and silane [15], silica nanoparticles addition into siloxane [16] and polysiloxane [17] were the examples of these types of studies. All of these studies showed some level of increase in thermal, mechanical and morphological properties of different type of synthetic polymers [18-20], while optical, electronic, magnetic, catalytic, chemical, and tribological properties and hydrophobicity $[14,16]$ of the surfaces changed significantly with the addition of nanoparticles into polymers [21,22]. Similarly, addition of nanoclays into biodegradable polymers improved mechanical, barrier, and thermal properties of the polymers in biomedical and food packaging applications [23-26].

\section{Research aims}

In this study, further improvements in nanofiller loaded biodegradable polymer coatings on marble protection was investigated. The protection efficiency of the bio-nano composite coatings was also explored for the inhibition or slowing down the effects of sulfation reaction on the Marmara marble surfaces.

\section{Material and methods}

\subsection{Preparation of marble samples}

Marmara marble has been widely used as natural stone at historic monuments and statues in the Marmara and Aegean regions. It is mainly composed of calcite minerals and has a moderate density $\left(2.7 \mathrm{~g} \mathrm{~cm}^{-3}\right)$ and low porosity $(0.2 \%)$ values [5]. Marble slabs were prepared by cutting them into rectangular shape (nearly $1.5 \mathrm{~cm} \times 1 \mathrm{~cm} \times 0.15 \mathrm{~cm}$ ) and polished with 400 -grit silicon carbide powder. Then, the samples were cleaned ultrasonically in deionized water to remove fine particulates, and dried at $105^{\circ} \mathrm{C}$. Marble slabs were kept in a desiccator to bring them into a constant weight prior the use.

\subsection{Preparation of biopolymer nanocomposite coatings}

PLA (PL-65, intrinsic viscosity: $6.5 \mathrm{dl} / \mathrm{g}$, Purac Biomaterials) was dissolved in chloroform approximately 8 hours at room temperature by using magnetic stirrer. Similarly, montmorillonite (MMT) clay (Cloisite 10A, d = $1.92 \mathrm{~nm}$ basal spacing, Southern Clay Products
Inc.), modified with quaternary ammonium salt (2MBHT, dimethyl, benzyl, hydrogenated tallow), was also dispersed in chloroform at different concentrations ( $0,2,5$ and $7 \%$ by weight respectively) and sonicated for an hour. Later, these solutions were mixed and stirred approximately for 15 hours at the room temperature and sonicated approximately for an hour.

\subsection{Coating of marble samples}

Clean marble slabs were coated by neat PLA and PLA/MMT composites (called as PLA/MMT2, PLA/MMT5 and PLA/MMT7 based on prepared concentrations) using by dip-coating apparatus (Nimadipper) at room temperature with a $100 \mathrm{~mm} \mathrm{~min}^{-1}$ retraction rate. Solvent was removed from coatings by keeping in oven at $40^{\circ} \mathrm{C}$ for several hours. The average thickness of coating was measured between $15-25 \mu \mathrm{m}$ by Scanning Electron Microscope (SEM), and the coated surface areas of marble were used to calculate amount of the coating agent on the each marble by taking into account of polymer percentage in the coated solution and the amount on surface ranged between 4 and $5 \mathrm{~g} \mathrm{~m}^{-2}$ for the all coated marbles.

\subsection{Identification and characterization of the surface and physical properties}

The film samples used for the determination of montmorillonite dispersion in polymer matrices were analyzed by using X-Ray Diffraction (XRD) and Scanning Tunnel Electron Microscopy (STEM), while protection performance was investigated by the measurement of surface roughness, wettability, water vapor permeability, capillary water absorption, and color changes on the uncoated and coated marble surfaces.

X-Ray Diffraction (XRD) analysis of the coatings were conducted by using Philips X'Pert Pro MRD with $\mathrm{Cu} K \alpha$ radiation $(\lambda=1.542 \mathrm{~nm})$ under a voltage of $40 \mathrm{kV}$ and a current of $40 \mathrm{~mA}$ between $2^{\circ}$ and $8^{\circ}$. Basal spacings of layered silicates in the PLA matrix were calculated by using Bragg's Law Eq. (1), where $\lambda$ corresponds to the wavelength of the X-ray source used, $\theta$ is the diffraction angle measured and $\mathrm{d}$ is the spacing between diffractional lattice planes.

$\lambda=2 d \sin \theta$

Surface wettability of the samples was determined by measuring the static contact angle with deionized water using goniometer (Kruss-G10). The samples' contact angle values were calculated from the average of ten measurements on the surface of each sample and the average value with standard deviation was reported.

The water vapor permeability of uncoated and coated marble experiments were conducted on circular samples. Each of the samples replaced in the partially water filled (1/2) cylindrical PVC containers. The samples were fixed in these containers in triplicates. Then, their lids were closed and put into the oven at a temperature of $40^{\circ} \mathrm{C}$, and relative humidity around $50 \%$. The containers were weighed every $24 \mathrm{~h}$, the differences in weight were used to calculate the water vapor fluxes for uncoated and coated plates. The details of the experiment and calculations were given in our previous work [5]. Capillary water absorption (WCA) of samples was measured by gravimetric sorption technique, while color variation was determined using a colorimeter (Avantes). According to Hunter system; $L$, a, and b values were averaged from ten readings across for each coated marble. In this system, color is represented as a position in a three-dimensional sphere where the vertical axis $\mathrm{L}$ indicates the lightness (ranging from black to white), and the horizontal axes, indicated by a and $b$, are the chromatic coordinates (ranging from a: greenness to redness and $b$ : blueness to 


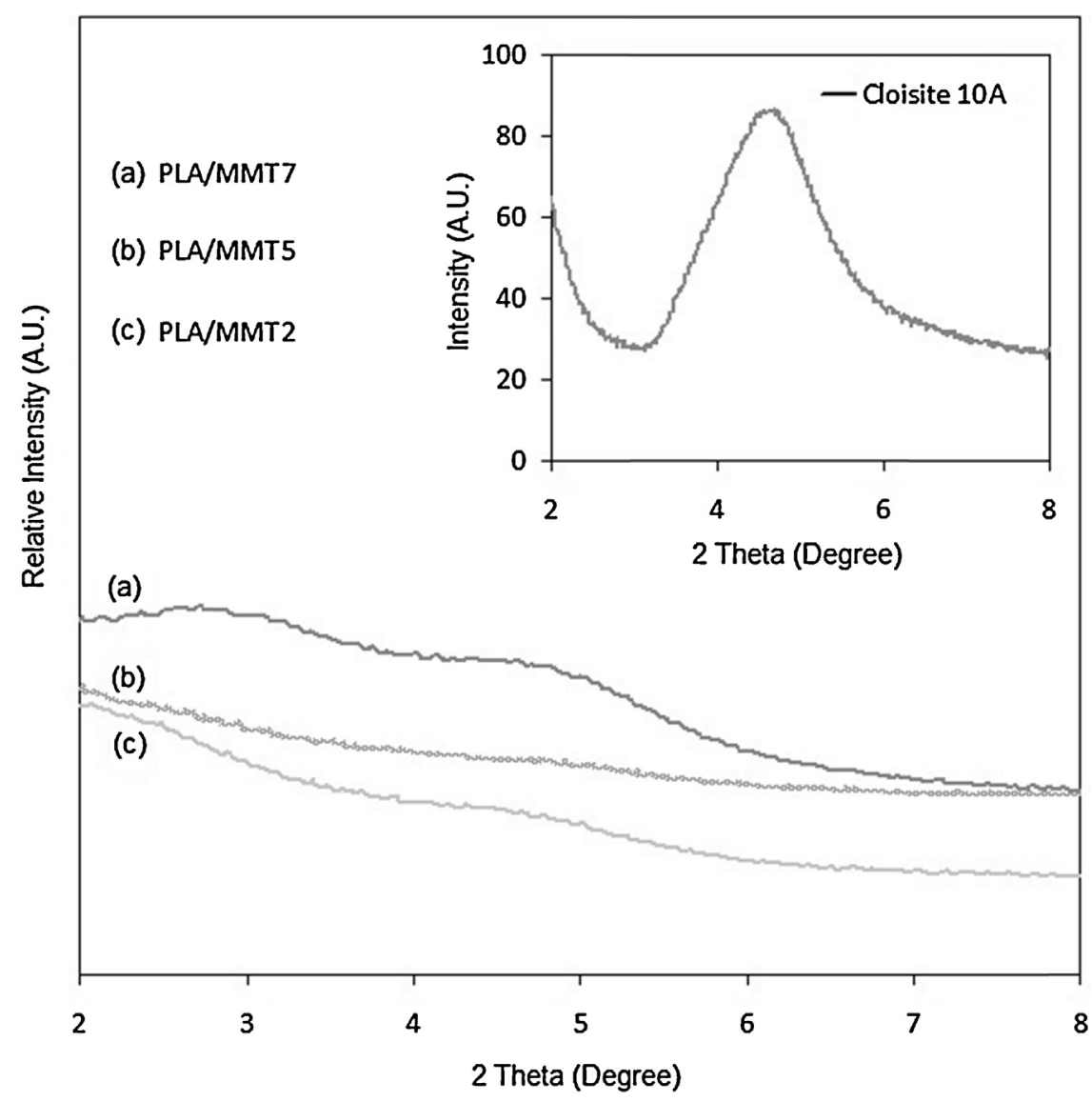

Fig. 1. XRD chromatogram of Cloisite $10 \mathrm{~A}$, and film samples of polymer-nanoclay composites.

yellowness). The total color difference $(\Delta \mathrm{E})$ can be calculated with the following equation:

$\Delta E=\sqrt{\Delta L^{2}+\Delta a^{2}+\Delta b^{2}}$

Uncoated marble was used as a background for color measurements of the coated marbles. Total color difference was calculated for coated samples. At least ten measurements were carried out for each sample on different position of samples [27].

\subsection{Determination of protection efficiency of coatings under acidic atmosphere}

The uncoated and coated marble plates were exposed in a dynamic 8 ppm $\mathrm{SO}_{2}$-enriched atmosphere at around $100 \%$ relative humidity, and at room temperature in a reactor which was a modified from $10 \mathrm{~L}$ dessicator as a function of time for 180 days. The amount of gypsum formed on samples was found by leaching the exposed samples in deionized water containing hydrogen peroxide $\left(\mathrm{H}_{2} \mathrm{O}_{2}\right)$ and then sulphate ion concentration was determined by ion chromatography (Dionex-GP50-2). The protection efficiency of coatings was expressed as comparing the gypsum crust thickness of the coated and uncoated marble plates. The samples' crust thickness calculations were given in our previous work [5].

Due to the limitation of reactor capacity, all samples could not be run at once. Therefore, one set of neat PLA, 2, 5 and $7 \mathrm{wt} \%$ PLA/MMT coated and uncoated marble samples were placed in the reaction chamber as triplicates to determine the variation in crust thickness. At the end of the 30th day, the gypsum crust thicknesses of the triplicate samples were calculated. The obtained results were compared with each other by using relative standard deviation (RSD).

\section{Results and discussion}

\subsection{Structural characterization of bio-nano composite coatings}

The level of layered silicate delamination in the matrix is a critical issue for polymer nanocomposites. X-ray diffraction is the most commonly used technique to characterize the structure of nanocomposites. The distance between layers of the silicate can be determined by utilizing Bragg's law. If there is no change in basal reflection of the layered silicate polymer nanocomposites with respect to characteristic peak of nanoclay, it can be said that phase separated structure is obtained owing to incompatibility between the layered silicate and polymer matrix. Intercalated structures can be determined by monitoring peak shifts to lower angles and/or broader peaks as the spacing of the organoclay increases. Exfoliated structures do not give diffraction peaks since distances between layered silicate platelets are higher than the detection limit of XRD [21,28,29].

Basal spacing of $1.902 \mathrm{~nm}$ by Bragg's Law was calculated for Cloisite 10A. Complete disappearance of $<001>$ reflection of Cloisite $10 \mathrm{~A}$ nanoclay for 1 and 2 and $5 \mathrm{wt} \%$ Cloisite 10A loaded PLA coatings can be attributed to the increase in the interlayer spacing of clay platelets. Since the distances between layered silicates increased to more than $4.62 \mathrm{~nm}$ from $1.902 \mathrm{~nm}$, it can be taken as an indication of possible exfoliation of nanoclay platelets in PLA matrix. The diffraction peaks of the nanocomposite films (Fig. 1) containing $7 \mathrm{wt} \%$ clay shifted to lower angles with broader peaks showing intercalated flocculated structure. This can be explained by the consequence of the coalescence phenomena due to the strong interactions between the silicate platelets at the highest clay content as commonly reported in the literature [22,30-33]. The results indicated that high interaction between the layered silicates and 


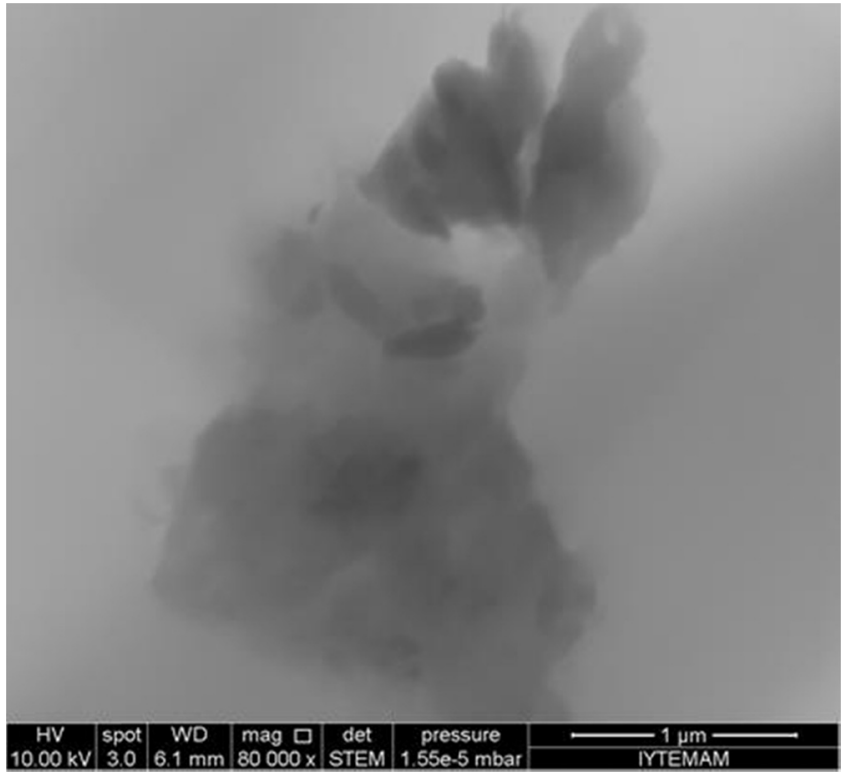

Fig. 2. STEM image of the PLA/MMT5 bio-nano composite film.

polymer matrix was achieved for only low clay loaded $(1,2$ and $5 \mathrm{wt} \%$ ) samples. The STEM picture (Fig. 2) of $5 \mathrm{wt} \%$ Cloisite $10 \mathrm{~A}$ loaded film also supported the presence of exfoliated structures. The exfoliated structure were also observed at low clay loading in poly(3-hydroxybutyrate-co-3) hydroxyhexanoate, biodegradable polyester matrices while intercalated structures were predominant at higher loadings with the addition of Clay 20A and Clay 25A into the polymer matrix [22].

\subsection{Surface characteristics of the uncoated and coated marbles}

\subsubsection{The surface wettability}

The average water contact angle was measured as $75 \pm 3.09^{\circ}$ for the uncoated marble surface which implies that marble surface was hydrophilic (Fig. 3). Coating with PLA polymer increased the contact angle of the surface to $96 \pm 2.51^{\circ}$ due to more hydrophobic nature of PLA compared to the marble surface. Addition of

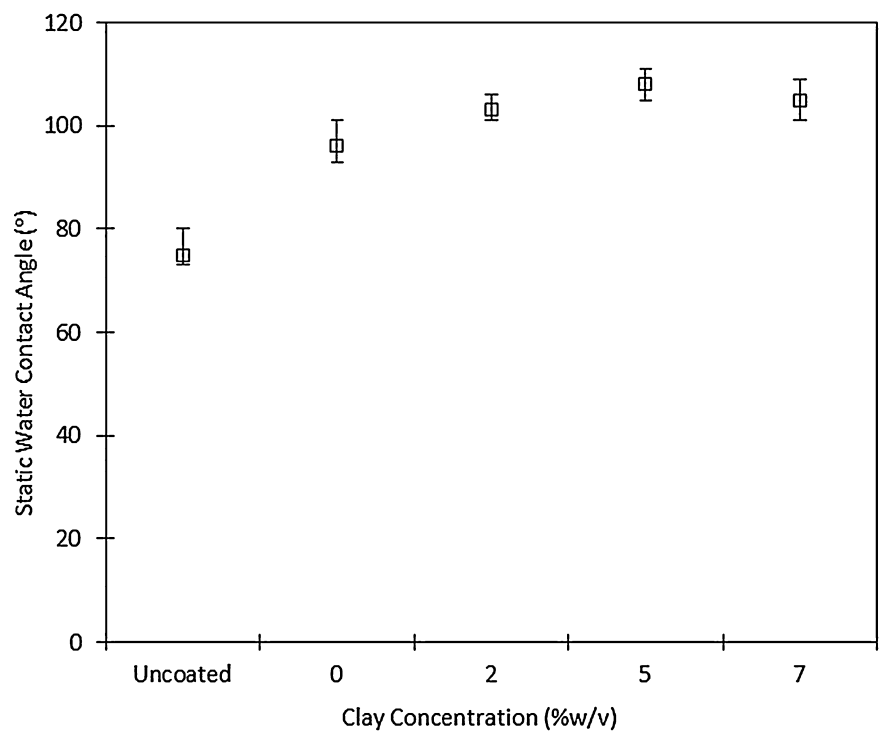

Fig. 3. Contact angle measurement of uncoated and neat PLA and PLA/MMT nanocomposite coated marbles. nanoclay into PLA showed a further increase in the contact angles of the surfaces. The value reached up to $108 \pm 2.49^{\circ}$ for the samples coated by PLA/MMT5 nanocomposite (Fig. 3). The degree of surface hydrophobicity indicated an increasing trend with increasing MMT content. Even a small addition of MMT increased surface hydrophobicity, and created a water-repellent surface. Unfortunately, the static contact angle value slightly decreased for PLA/MMT7 $\left(105 \pm 2.61^{\circ}\right)$. This is due to high level of clay loading resulted in agglomeration due to the strong interactions between clay particles. A critical limit of layered silicate content is reported by many authors, due to the poorer exfoliation of nanofillers resulting in lower performance of the properties [30-33]. Similar decreases were observed in several polymer/nano clay composite systems such as 6\% Cloisite 30B addition into Fluoline $\mathrm{CP}$ and Antipluviol $\mathrm{S}$ resins on the concrete surfaces [34].

\subsubsection{Water capillary absorption and water vapor permeability}

Gaseous pollutants dissolved in water penetrate into the stone by capillary absorption and accelerate stone deterioration. Waterrepellents prevent or reduce the water penetration into stone and diminish the effects of gaseous pollutants. Although, the surface is changed into a hydrophobic surface by coating, the water can penetrate to the stone by capillary absorption. Therefore, an overall protection strategy is needed against such invasion [16].

In this study, the average capillary water absorption of uncoated marble was nearly $4.17 \pm 0.19 \mathrm{mg} \mathrm{cm}^{-2} \mathrm{~h}^{-1}$. In the previous work of our group, a decrease in capillary water absorption for PLA coated Marmara marble was observed as well [5]. The addition of nanoclay filler to neat PLA showed further decrease in the capillary water absorption for all concentrations of PLA/MMT nanocomposite coatings on marble surfaces (Fig. 4). The percentage reduction in capillary absorption varied from $46 \%$ to $66 \%$ (PLA/MMT5) (Table 1). Decrease in capillary absorption was also reported for silica nanofiller added into polyalkysiloxane solution [14]. It was explained that lamellar nanofiller improved the moisture penetration resistance of the treated substrate through the pore blockage of the concrete, and lowered the diffusion properties of the polymer matrices. They found out that water capillary sorption was strongly dependent on the character of the

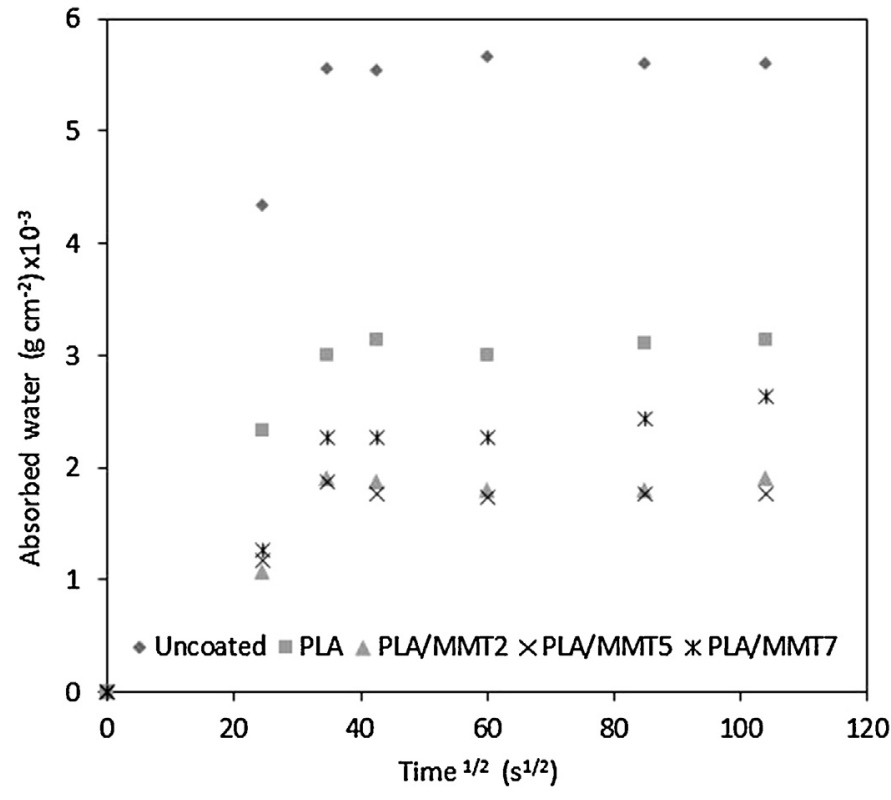

Fig. 4. Average capillary water absorption for uncoated and coated marble surfaces. 
Table 1

Water vapor transmission rate $\left(\mathrm{g} \cdot \mathrm{m}^{-2} \mathrm{~d}^{-1}\right)$, \% reduction in WVTR and WCA.

\begin{tabular}{llll}
\hline Sample & $\begin{array}{l}\text { WVTR }(n=3) \\
\left(\mathrm{g} \cdot \mathrm{m}^{-2} \cdot \mathrm{d}^{-1}\right)\end{array}$ & $\begin{array}{l}\text { \% Reduction of } \\
\text { WVTR }\end{array}$ & $\begin{array}{l}\text { \% Reduction of } \\
\text { WCA }\end{array}$ \\
\hline Uncoated & $0.00893 \pm 0.01387$ & & \\
PLA & $0.00613 \pm 0.00586$ & $31 \pm 6.5$ & $46.0 \pm 1.8$ \\
PLA/MMT2 & $0.00392 \pm 0.00433$ & $56 \pm 4.8$ & $65.6 \pm 3.6$ \\
PLA/MMT5 & $0.00363 \pm 0.00379$ & $59 \pm 4.2$ & $66.4 \pm 5.4$ \\
PLA/MMT7 & $0.00406 \pm 0.00025$ & $54 \pm 2.8$ & $59.8 \pm 5.4$ \\
\hline
\end{tabular}

resins (hydrophilic or hydrophobic, coating or pore liner) and the nanoclay addition [34].

The average water vapor transmission rate (WVTR) of the uncoated marbles was determined as nearly $0.00197 \pm 0.0032 \mathrm{~g} \mathrm{~cm}^{-2} \mathrm{~d}^{-1}$. The water vapor transmission of the uncoated Marmara marble was found out as $0.0045 \mathrm{~g} \mathrm{~cm}^{-2}$ $\mathrm{d}^{-1}$ in our previous study [5], the variation is acceptable due to the natural structure of the stone. The water vapor transmission was evaluated as a function of nanoclay concentration. As seen in Table 1, a thin coating of PLA on marble surfaces resulted in $31 \pm 6.6 \%$ reduction in water vapor transmission rate. Continuous decrease in water vapor permeation with increasing clay content was achieved, and the WVTR's of coatings decreased with a similar trend of WCA (Table 2). It is noteworthy that addition of nanoclay to biodegradable polymer enhanced the water vapor barrier properties of the polymer. Increased water vapor barrier of the PLA/MMT nanocomposite coating can be interpreted as a result of layered silicate exfoliation and intercalation in the PLA polymer matrix. When layered silicates effectively distributed in the polymer matrix, impermeable obstacles to permeating water vapor molecules are created due to the better interaction between the hydrophobic nature of clay particles and hydrophobic polymer matrix, PLA. Because of this, the effective pathway of permeating water molecule increases and the water vapor permeability decreases. This was observed in similar biodegradable polymer nanocomposite studies [24,25,34].

\subsubsection{Color alteration}

Transparency is one of the essential properties of the surface coating which should not change the optical appearance of the stone. Conducted color variation measurement determined the optical appearance of coated marble, which is not related to protection properties of the coating materials.

If the value of total color difference $(\Delta E)$ is $<1$, it can be considered that the difference is not distinguished by the human eye; if $1<\Delta \mathrm{E}<3$, it is regarded as clinically acceptable; and $\Delta \mathrm{E}>3.3$ refers the appearance is not acceptable clinically [35]. The calculated total color difference $(\Delta \mathrm{E})$ values for neat PLA, PLA/MMT2, and PLA/MMT5 coated marbles were $1.43 \pm 0.60,1.87 \pm 0.85$, $2.99 \pm 0.41$, respectively all of which were clinically acceptable $(1<\Delta \mathrm{E}<3.3)$. However, the measured value $(4.93 \pm 0.96)$ for PLA/MMT7 coating agent showed that it was not clinically acceptable (Fig. 5). Similar trend was also observed for WCA, WVTR, and surface wettability of PLA/MMT7 coated surfaces due to the low level of clay dispersion.

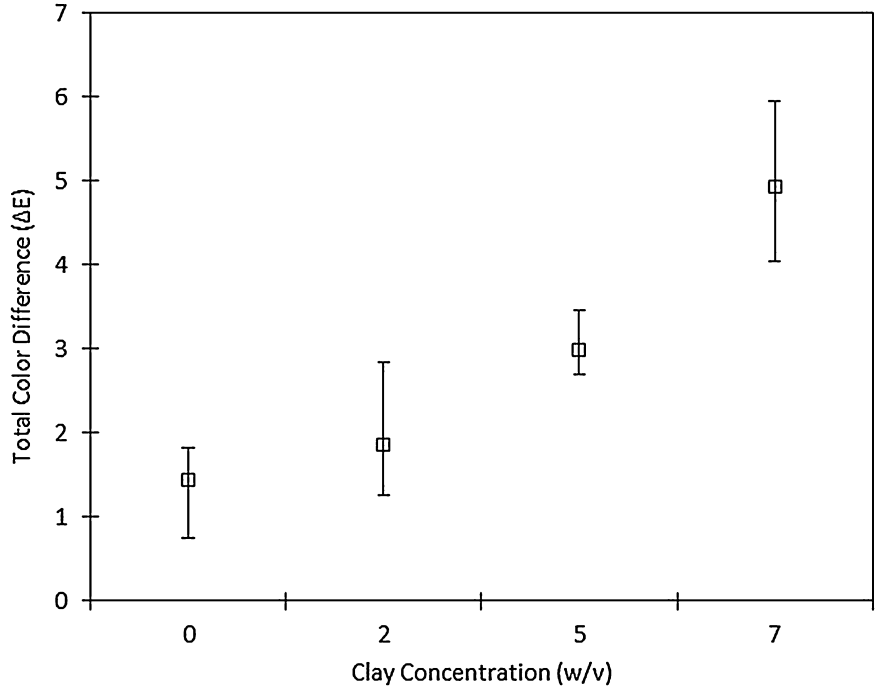

Fig. 5. The total color difference $(\Delta \mathrm{E})$ of the neat PLA, and 2, 5, 7\% PLA/MMT nanocomposite coated marbles.

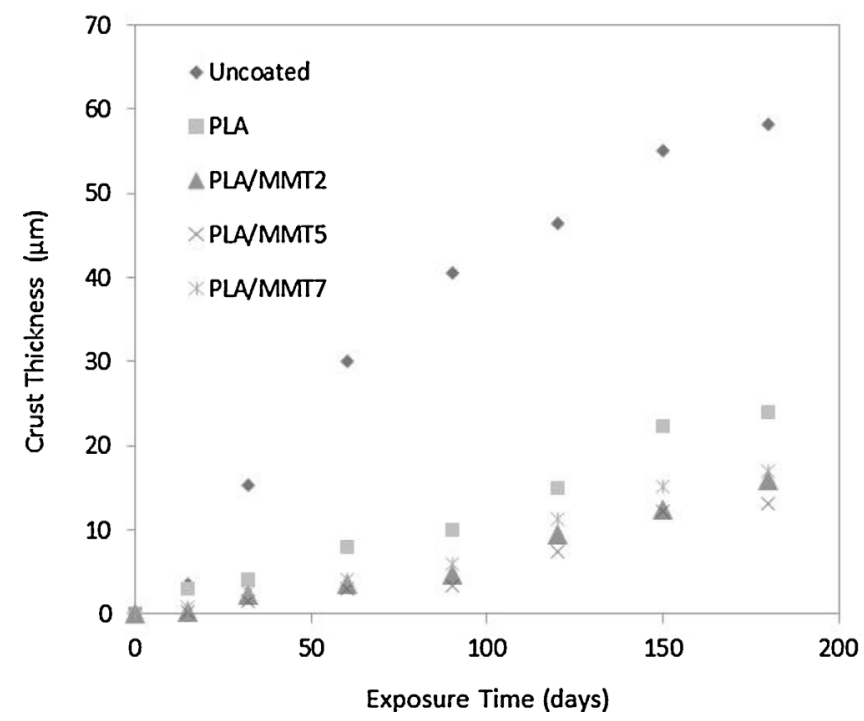

Fig. 6. Gypsum crust thicknesses of uncoated and nanocomposite coated marbles.

\subsection{Protection efficiency of coatings in acidic atmosphere}

After exposure of uncoated and coated marble slabs to $\mathrm{SO}_{2}$ and water vapor in the reaction chamber, $\mathrm{SO}_{2}$-calcite reaction was investigated by the measurement of the total sulfate at the end of exposure durations of $15,32,45,60,75,90,120$ and 180 days respectively. The measured total sulfate concentration was used to calculate gypsum crust thicknesses as described by Ocak et al. [5] for uncoated and PLA/MMT composite coated marble slabs (Fig. 6).

Inhibition of gypsum formation on the surface of neat PLA coated marbles was observed 2-3 times lower than the uncoated marbles. In the meantime, PLA/MMT coated surfaces showed significant reduction (4-5 times) in the crust formation with the addition of

Table 2

Precision of the sulfation experiment based on the crust thickness $(\mu \mathrm{m})$ for each coating $(n=3)$ in the same batch.

\begin{tabular}{|c|c|c|c|c|c|}
\hline Samples & Uncoated & Neat PLA & PLA/MMT2 & PLA/MMT5 & PLA/MMT7 \\
\hline Mean \pm SD & $11.77 \pm 0.34$ & $3.13 \pm 0.067$ & $0.37 \pm 0.061$ & $0.57 \pm 0.085$ & $0.76 \pm 0.041$ \\
\hline RSD\% & 2.9 & 2.1 & 16 & 15 & 5.3 \\
\hline
\end{tabular}




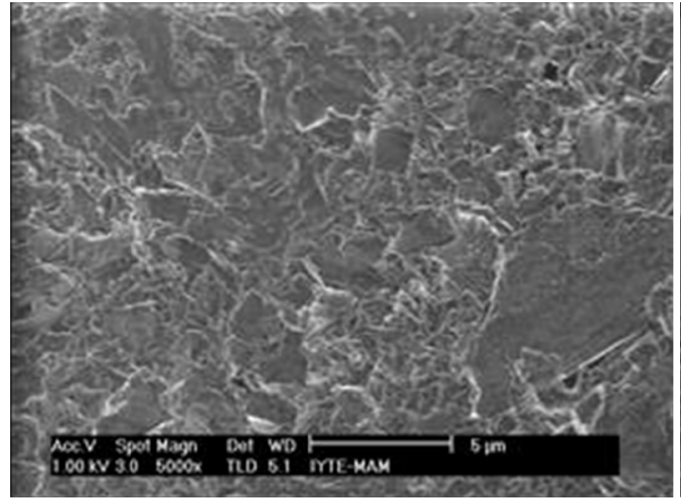

a)

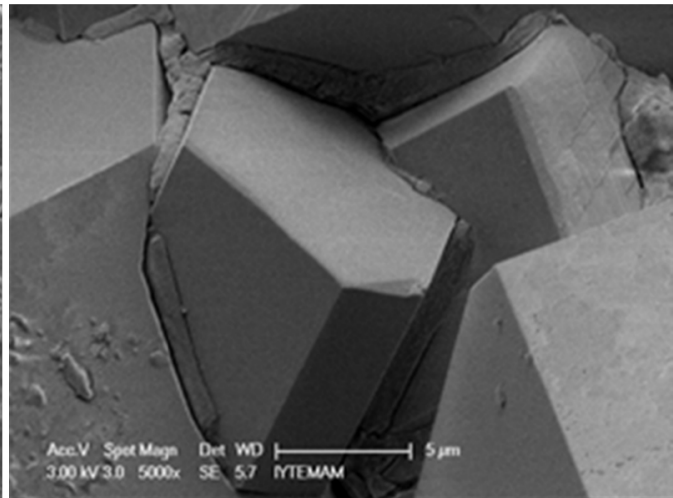

b)

Fig. 7. SEM images of the uncoated marble slabs before (a) and after (b) 180 days $\mathrm{SO}_{2}$-calcite reaction

nanoclay in the PLA polymer. It could be said that the addition of nanoclay enhanced the performance of the coating agent under acidic environment.

To determine the repeatability of the experiment, triplicate samples in each coating composition were placed in the reaction chamber, and at the end of the 30th day of the experiment, gypsum crust thicknesses were calculated (Table 2). The crust thickness RSD (\%) values were found to be lower than $20 \%$.

The changes on surfaces due to products of sulfation reaction, degradation of the biopolymer coating were monitored by using scanning electron microscope (SEM) at defined time intervals. The calcite crystals were easily observed on the uncoated marble surfaces before reaction (Fig. 7a) due to the dominancy of calcite crystals in marble components. However, the homogenous coverage of huge gypsum crystals on the marble surface after 180 days of exposure to water vapor saturated $\mathrm{SO}_{2}$ (Fig. 7b) was also apparent. In contrast with uncoated marbles, any significant sulfation reaction products were not observed on the coated surfaces after exposure. Some small gypsum crystals were rarely observed on the neat PLA coated surfaces (Fig. 8a). Homogenous pore distributions on the surface of the coated marbles were interpreted as a degradation of polymer (Fig. 8).

In order to indicate the protection efficacy of coatings on the marble surfaces, semi-coated marble slabs were also prepared. The

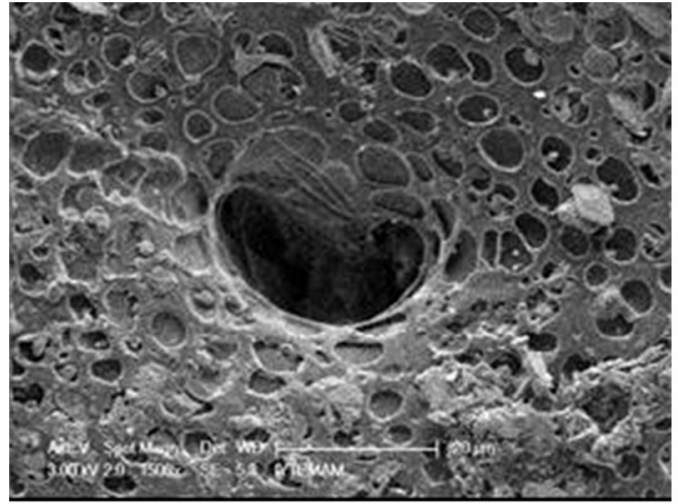

(a)

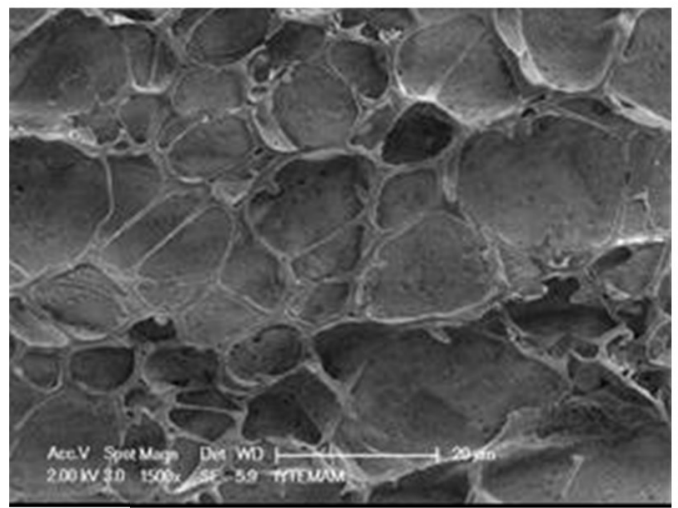

(c)

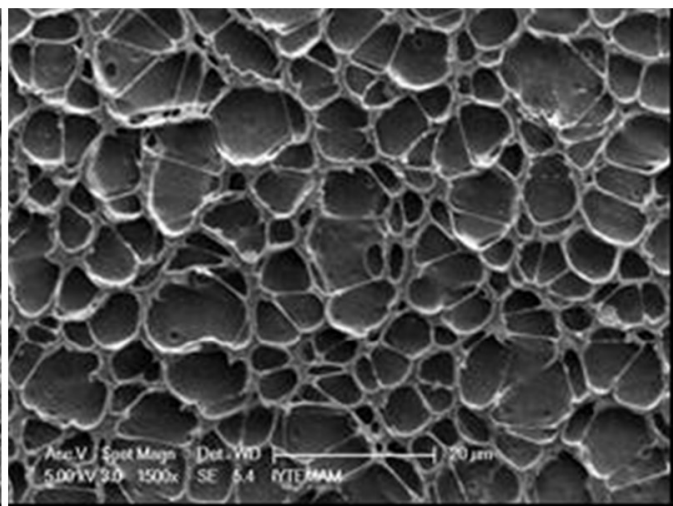

(b)

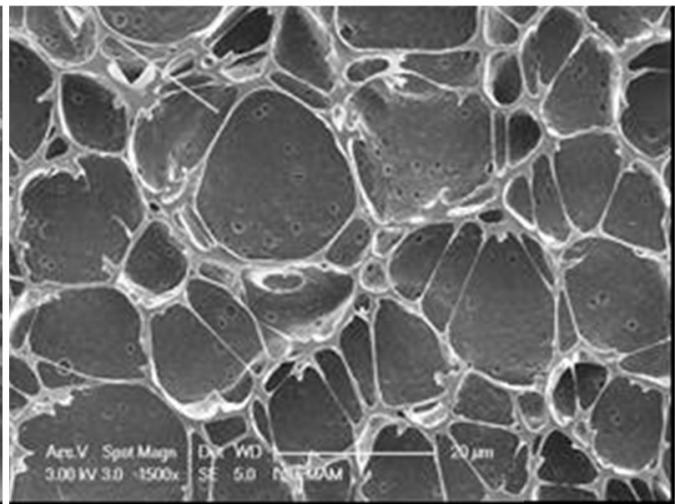

(d)

Fig. 8. SEM images of the neat PLA (a), 2 (b), 5 (c) and 7\% PLA/MMT (d) after 180 days $\mathrm{SO}_{2}$-calcite reaction. 


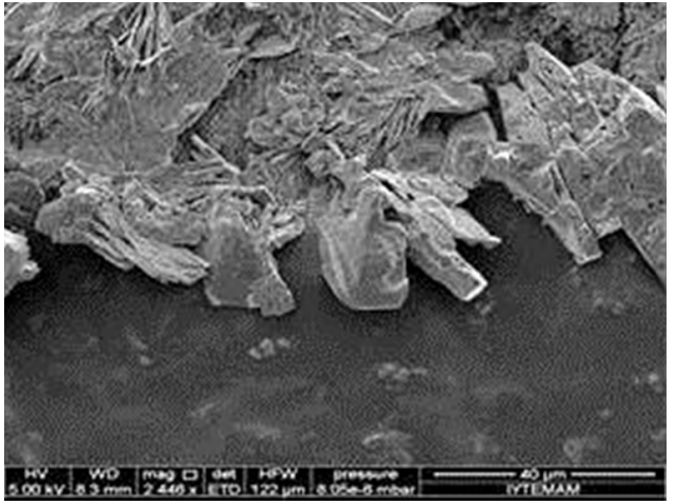

(a)

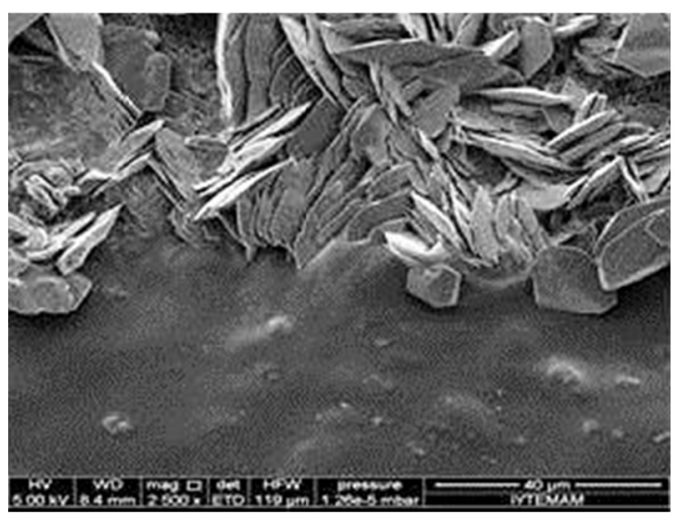

(b)

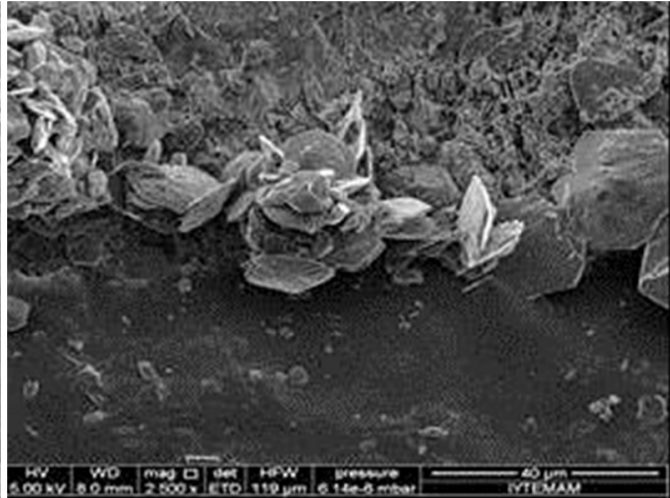

(b)

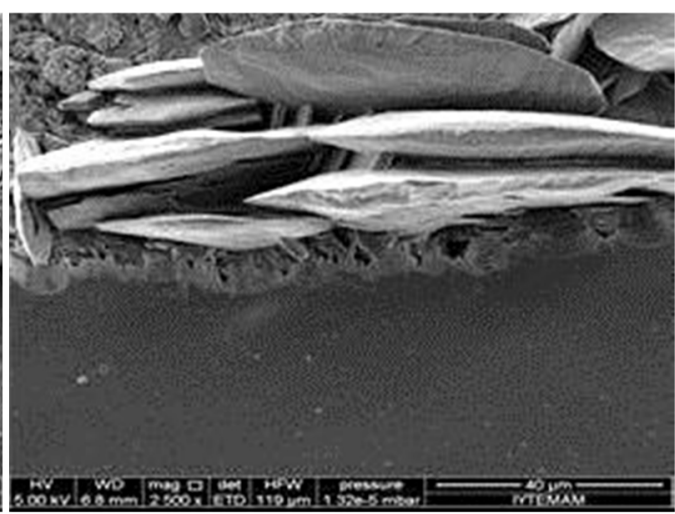

(d)

Fig. 9. SEM images of the sulfation products on the neat PLA (a), 2 (b), 5 (c) and 7\% PLA/MMT (d) semi-coated surfaces after 180 days SO ${ }_{2}$-calcite reaction.

difference of the sulfation product crystals between the coated and uncoated sides were observed more remarkably after 180 days $\mathrm{SO}_{2}$ calcite exposure (Fig. 9). As seen in the SEM images, gypsum crystals were formed anywhere on the non-protected (uncoated) sides of the marble slabs.

\section{Conclusion}

The addition of nanoclay into polymer increased the hydrophobicity of the marble surface, and as a result decreased water vapor absorption of the polymer. Significant difference was observed among the coated surfaces compared to uncoated (control) and neat PLA coated surfaces. The observed gypsum crust thickness of coated marble was approximately five times lower than the uncoated marble, and two times lower than neat PLA coated marbles after 180 days $\mathrm{SO}_{2}$-water vapor exposure due to well dispersion of inorganic layer of clay throughout the polymer matrix.

The degree of surface hydrophobicity increased with increasing Cloisite 10 A content. As degree of surface hydrophobicity increased, capillary water absorption and water vapor transmission decreased indicating a possible relationship between contact angle changes and water vapor barrier due to presence of nanoclays in the polymer matrix. The reduction of capillary water absorption and water vapor permeability would be due to the presence of exfoliated nanoclays on the surface limiting water molecules to be absorbed by the polymer matrix and/or due to the decreased affinity of water molecules with more hydrophobic PLA coating.

Reversibility of coating agent is one of the important parameter in the protection of historical monuments; therefore, observation of biodegradability of the composite implies the indication of reversibility of coating. Furthermore, nanoclay addition extended the lifetime of biodegradable polymer compared to our previous study [5,27]. As a result, PLA/MMT coating agent seems to be a promising agent for the protection studies.

\section{Acknowledgements}

We thank The Scientific and Technical Research Council of Turkey (TUBITAK) for financial support to 108M335 project, Environmental Research Center and Material Research Center of the Izmir Institute of Technology for the analysis. We also thank to Prof Dr. Orhan Öztürk (Department of Physics of Izmir Institute of Technology) for the thin film XRD analysis. The Southern Clay Products and Purac Biomaterials are also acknowledged for providing Cloisite 10A nanoclay and Purasorb PL-65 respectively used in this study.

\section{References}

[1] N. Marinoni, M.P. Birelli, C. Rostagno, A. Pavese, The effects of atmospheric multipollutants on modern concrete, Atmos. Environ. 37 (2003) 4701-4712.

[2] K.L. Gauri, N.P. Kulshreshtha, A.R. Punuru, A. Chowdhury, Rate of decay of marble in laboratory and outdoor exposure, J. Mater. Civil Eng. 1 (1989) 73-83.

[3] H. Boke, H. Göktürk, E.N. Caner-Saltık, Ş. Demirci, Effect of airborne particles on $\mathrm{SO}_{2}$-calcite reaction, Appl. Surf. Sci. 140 (1999) 70-82.

[4] K.L. Gauri, J.K. Bandyopadhyay, Carbonate stone, chemical behavior, durability and conservation, JohnWiley \& Sons, New York, 1999.

[5] Y. Ocak, A. Sofuoglu, F. Tihminlioglu, H. Boke, Protection of marble surfaces by using biodegradable polymers as coating agent, Prog. Org. Coatings 66 (3) (2009) 213-220.

[6] T. Poli, L. Toniolo, O. Chiantore, The protection of different Italian marbles with two partially flourinated acrylic copolymers, Appl. Phys. A 79 (2004) 347-351.

[7] L. Toniolo, T. Poli, V. Castelvetro, A. Manariti, O. Chiantore, M. Lazarri, Tailoring new fluorinated acrylic copolymers as protective coatings for marble, J. Cult. Herit. 3 (2002) 309-316. 
[8] A. Tsakalof, P. Manoudis, I. Karapanagiotis, I. Chryssoulakis, C. Panayiotou, Assessment of synthetic polymeric coatings for the protection and preservation of stone monument, J. Cult. Herit. 8 (2007) 69-72.

[9] H. Boke, K.L. Gauri, Reducing marble- $\mathrm{SO}_{2}$ reaction rate by the application of certain surfactants, Water Air Soil Pollut. 142 (2003) 59-70.

[10] F. Cappitelli, C. Sorlini, Microorganisms attack synthetic polymers in items representing our cultural heritage, Appl. Environ. Microbiol. 74 (2008) 564-569.

[11] A.P. Kumar, D. Depan, N.S. Tomer, R.P. Singh, Nanoscale particles for polymer degradation and stabilization: trends and future perspectives, Prog. Polymer Sci. 34 (2009) 479-515

[12] M. Zielecka, E. Bujnowska, Silicone-containing polymer matrices as protective coatings: properties and applications, Prog Org. Coatings 55 (2006) 160-167.

[13] C. Su, J. Li, H. Geng, Q. Wang, Q. Chen, Fabrication of an optically transparent super-hydrophobic surface via embedding nano-silica, Appl. Surf. Sci. 253 (2006) 2633-2636.

[14] P. Manoudis, S. Papadopoulou, I. Karapanagiotis, A. Tsakalof, I. Zuburtikudis, C. Panayiotou, Polymer silica nanoparticles composite films as protective coatings for stone-based monuments, J. Phys. 61 (2007) 1361-1365.

[15] K.Y. Christopher, M. Leung, Z. Hong-Gang, K. Jang-Kyo, S.W. Ricky, Use of polymer/organoclay nanocomposite surface treatment as water/ion barrier for concrete, J. Mater. Civil Eng. 20 (2008) 484-492.

[16] P. Manoudis, A. Tsakalof, I. Karapanagiotis, I. Zuburtikudis, C. Panayiotou, Fabrication of super-hydrophobic surfaces for enhanced stone protection, Surf. Coatings Technol. 203 (2009) 1322-1328.

[17] L. Ferri, P.P. Lottici, A.L. Lorenzic, A. Monteneroc, E.S. Marianid, Study of silica nanoparticles-polysiloxane hydrophobic treatments for stone-based monument protection, J. Cult. Herit. 12 (2011) 356-363.

[18] D.R. Paul, L.M. Robeson, Polymer nanotechnology: nanocomposites, Polymer 49 (2008) 3187-3204.

[19] S.K. Sharma, S.K. Nayak, Surface modified clay/polypropylene (PP) nanocomposites: effect on physico-mechanical, thermal and morphological properties, Polymer Degradation Stability 94 (2009) 132-138.

[20] S. Wacharawichanant, S. Thongya, A. Phutthaphan, C. Eiamsam-ang, Effect of particle sizes of zinc oxide on mechanical, thermal and morphological properties of polyoxymethylene/zinc oxide nanocomposites, Polymer Test. 27 (2008) 971-976.

[21] N. Mittal, Polymer nanotube nanocomposites: synthesis, properties, and applications, John Wiley \& Sons, New Jersey, 2010.
[22] X. Zhang G. Lin, R. Abou-Hussein, M.K. Hassan, I Noda, J.E. Mark, Some novel layered-silicate nanocomposites based on a biodegradable hydroxybutyrate copolymer, Eur. Polymer J. 43 (2003) 3128-3135.

[23] N. Bitinis, M. Hernandez, R. Verdejo, J.M. Kenny, M.A. Lopez-Manchado, Recent advances in clay/polymer nanocomposites, Adv. Mater. 23 (2011) 5229-5236.

[24] O. Ozcalik, F. Tihminlioglu, Barrier properties of corn zein nanocomposite coated polypropylene films for food packaging applications, J. Food Eng. 114 (2013) 505-513.

[25] H. Oguzlu, F. Tihminlioglu, Preparation and barrier properties of chitosan layered silicate nano composites films, Macromol. Symp. 298 (1) (2010) 91-98.

[26] L. Di Maio, P. Scarfato, M.R. Milana, R. Feliciani, M. Denaro, G. Padula, L. Incarnato, Bionanocomposite polylactic acid/organoclay films: functional properties and measurement of total and lactic acid specific migration, Packag. Technol. Sci. 27 (2014) 535-547.

[27] Y. Ocak, Use of bio-nano composites as protective coating on natural stone surfaces, PhD thesis, Izmir Institute of Technology, Turkey, 2013.

[28] J. Koo, Polymer nanocomposites: processing, characterization, and applications, 1st ed., McGraw-Hill, New York, 2006.

[29] S. Pavlidou, C.D. Papaspyrides, A review on polymer-layered silicate nanocomposites, Prog. Polymer Sci. 33 (2008) 1119-1198.

[30] L. Petersson, K. Oksman, Biopolymer based nanocomposites: comparing layered silicates and microcrystalline cellulose as nanoreinforcement, Composites Sci. Technol. 66 (2006) 2187-2196.

[31] S. Tunc, H. Angellier, Y. Cahyana, P. Chalier, N. Gontard, E. Gastaldi, Functiona properties of wheat gluten/montmorillonite nanocomposite films processed by casting, J. Membr. Sci. 289 (2007) 159-168.

[32] J. Luecha, N. Sözer, J.L. Kokini, Synthesis and properties of corn zein/montmorillonite nanocomposite films, J. Mater. Sci. 45 (2010)3529-3537.

[33] P. Scarfato, L. Di Maio, M.L. Fariello, P. Russo, L. Incarnato, Preparation and evaluation of polymer/clay nanocomposite surface treatments for concrete durability enhancement, Cement Concrete Composites 34 (2012) 297-305.

[34] J.W. Rhim, S.I. Hong, C.S. Ha, Tensile, water vapor barrier and antimicrobia properties of PLA/nanoclay composite films, LWT-Food Sci. Technol. 42 (2009) 612-617.

[35] A. Vichi, M. Ferraria, C.L. Davidson, Color and opacity variations in three different resin-based composite products after water aging, Dent. Mater. 20 (2004) 530-534. 